\title{
Preface to the special issue of the International Conference on Dynamical Systems - Theory and Applications (DSTA 2017)
}

\author{
Jan Awrejcewicz ${ }^{\mathrm{a} *}$ (D) \\ Elbert Macau ${ }^{b}$ \\ a Department of Automation, Biomechanics and Mechatronics, Lodz University of Technology, 1/15 Stefanowski St., 90-924 Lodz, Poland. \\ E-mail: jan.awrejcewicz@p.lodz.pl \\ b Instituto Nacional de Pesquisas Espaciais - INPE. v. dos Astronautas, 1.758 - Jardim da Granja, São José dos Campos, Brasil. \\ E-mail: elbert.macau@inpe.br \\ ${ }^{*}$ Corresponding author
}

http://dx.doi.org/10.1590/1679-78255471

We are pleased to present this Special Issue of the Latin American Journal of Solids and Structures, which is devoted to the 14th International Conference on "Dynamical Systems - Theory and Applications" (DSTA 2017) held on December 11-14, 2017 in Lodz, Poland. The conference has been repeatedly organized by the Department of Automation, Biomechanics and Mechatronics of the Lodz University of Technology since 1992. The main reason of the $14^{\text {th }}$ edition of the conference was to provide the researchers the adequate platform to share and discuss their latest research results, observations and most modern state and perspective of the dynamical systems. The following topics have been discussed during the DSTA 2017 conference: modeling, simulation, stability and control of nonlinear dynamical systems including different disciplines of science, bioscience and engineering.

The Scientific Committee of the conference included the following well-known researchers: H. Altenbach Germany, M. Alves - Brazil, J. Ambrosio - Portugal, I.V. Andrianov - Germany, J. Awrejcewicz - Chairman, Poland, J.M. Balthazar - Brazil, B. Birnir - USA, T. Burczyński - Poland, F. Chernousko - Russia, F. Dohnal - Switzerland, V.-F. Duma Romania, I. Elishakoff - USA, N. Ferreira - Portugal, B. Gallacher - UK, O. Gendelman - Israel, O. Gottlieb - Israel, P. Hagedorn - Germany, K. (Stevanovic) Hedrih - Serbia, I. Kovacić - Serbia, J. Kozanek - Czech Republic, V.A. Krysko Russia, L.V. Kurpa - Ukraine, C.-H. Lamarque - France, S. Lenci - Italy, G.A. Leonov - Russia, A. Luo - USA, E. Macau Brazil, J.A. Machado - Portugal, N.M.M. Maia - Portugal, A.A. Martynyuk - Ukraine, G.I. Mikhasev - Belarus, Y. Mikhlin Ukraine, G. Olivar - Colombia, V.N. Pilipchuk - USA, C.M.A. Pinto - Portugal, J. Przybylski-Poland, Ch.H. Skiadas - Greece, S. Theodossiades - UK, J.J. Thomsen - Denmark, F. Udwadia - USA, F. Verhulst - The Netherlands, J. Warmiński - Poland, K. Zimmermann - Germany.

From all the papers presented during the conference, the committee selected a special set of six works of most interesting topics as well as best quality for this special issue. The authors of those papers were invited to prepare the extended versions of their works, which are summarized briefly as follows:

1. Grzelczyk and Awrejcewicz calculated the reflectance and transmittance of different optical birefringent networks sandwiched between two isotropic media. Optical phenomena were modeled using the $4 \times 4$ matrix method, which takes into account the effect of refraction and multiple reflections between plate interferences, both ordinary and extraordinary waves that occur in birefringent networks. As a result, some interesting reflection and transmission spectra as well as polar plots of the reflection or transmission coefficient have been obtained, reported and discussed. The illustrated results can be useful for understanding optical phenomena in numerous birefringent media.

2. Avanço et al. showed a mathematical model and numerical results obtained for the pendulum behavior when coupled to a DC generator. The model consists of a simple pendulum, vertically excited on its support and consequently exhibiting oscillations and rotations. The dynamic model involving the generator and the pendulum 
dynamics was developed and analyzed in this paper. Authors showed the bifurcation diagrams demonstrating doubling-period and saddle-node bifurcations with the chaos, the presence of which was verified by the Lyapunov exponents applied on the time series of the pendulum speed and position. Finally, authors analyzed the non-ideal interactions of a DC motor with a pendulum by a crank-shaft-slider mechanism and compared them with an ideal excitation of the pendulum.

3. Nowakowski et al. analyzed the wheel-flat defect as one of the many issues decreasing the level of and comfort in light rail vehicles. Wheel-flat defect could prove to be dangerous for the safety of the ride. Authors presented the algorithm, according to which the wheel-flat detection during tram passage is possible. Several vibration transducers were mounted on the rail and measured vibration amplitude during trams pass-by. The method presented in this paper points out a large equivalence in the interpretation of the outcomes and the efficiency in detecting flat spots on the wheels, verified in the real-life exploitation.

4. Czapla et al. presented the experimental results for material model of the sand, case of wet and dry probe. The methodology presented in this work includes a test in various ground conditions and different driving direction. Test results were acquired for dry and humid sand, for various tire tilt angle. The methodology presented in the article is based on test facility designed by authors and has unique abilities for direct traction loads measurement for various wheel-surface configurations.

5. Janzen et al. showed a parametrical analysis of an energy harvesting system based on a floating platform with a pendulum coupled to the top end of the structure. Authors considered that the ocean waves motion swings the platform in the vertical direction, which transfers energy to the pendulum, making it possible to convert mechanical energy induced by the ocean wave into rotational motion due the pendulum and after in electric energy due the generator. This work was based on the Brazilian's coast characteristics. Numerical and experimental results showed the efficiency of the conversion of mechanical energy provided by the pendulum into electric power.

6. Kurpa et al. (2019) proposed a method of investigation of free vibrations of laminated functionally graded shallow shells with complex shape of the planform. The presented method was based on the theory of R-functions and Ritz variational method. Formulation of the problem was carried out using the first-order (Timoshenko's type) refined theory of shallow shells. Different types of boundary conditions, including clamped, simply supported, free edge and their combinations, were studied. The proposed method and the created computer code were examined on test problems for shallow shells with rectangular planforms. Effects of different material distributions, mechanical properties of the constituent materials, lamination scheme, boundary conditions and geometrical parameters on natural frequencies were shown and analyzed.

We hope that the readers of the Latin American Journal of Solids and Structures journal will find the presented works useful, interesting and will use them as the stimulus for their further research. We would like to thank the Editorin-Chief Marcílio Alves as well as all the reviewers and editors for their contribution and cooperation during realization of this special issue.

\section{References}

Grzelczyk, D., Awrejcewicz, J., (2019). Calculation of reflectance and transmittance of optical birefringent networks based on cholesteric liquid crystals. Latin American Journal of Solids and Structures.

Avanço, R.H., Tusset, A.M., Suetake, M., Navarro, H.A., Balthazar, J.M., Nabarrete, A., (2019). Energy harvesting through pendulum motion and DC generators. Latin American Journal of Solids and Structures.

Nowakowski, T., Komorski, P., Szymański, G.M., Tomaszewski F., (2019). Wheel-flat detection on trams using envelope analysis with Hilbert transform. Latin American Journal of Solids and Structures.

Czapla, T., Fice, M., Niestrój R., (2019). Wheel-surface model parameters estimation: sand humidity influence on traction effort of all-terrain unmanned vehicle. Latin American Journal of Solids and Structures.

Janzen, F.C., Tusset, A.M., Balthazar, J.M., Rocha, R.T., Lima, J.J., Nabarrete A., (2019). Offshore energy harvesting of a marine floating pendulum platform model. Latin American Journal of Solids and Structures.

Kurpa, L., Shmatko, T., Awrejcewicz, J., (2019). Vibration analysis of laminated functionally graded shallow shells with clamped cutout of the complex form by the Ritz method and the R-functions theory. Latin American Journal of Solids and Structures. 